\title{
Pemanfaatan Citra Landsat Untuk Klasifikasi Tutupan Lahan Lanskap Perkotaan Kota Palu
}

\author{
ANDI CHAIRUL ACHSAN ${ }^{1}$ \\ 1. Program Studi Perencanaan Wilayah dan Kota, Jurusan Teknik Arsitektur, \\ Fakultas Teknik, Universitas Tadulako, Palu 94118 Indonesia \\ *E-mail: andichairulachsan@gmail.com
}

\section{ABSTRACT \\ The Use of Landsat Image For Land Cover Classification On Urban Landscape Of Palu City}

One of effort that can be done for knowing urban development is with seeing land cover information. By land cover map can be kown the information of kind of land cover, area of each land cover and thedistribution of the use of space on the region. Satellite image is one of media that can be used for obtaining the information of land cover. This research purpose was for analysing the use of landsat image for determining the land cover classification on urban landscape using geographic information system. Classification proces of satellite image was started by merging band and cropping image, geometric correction and classification using image classification and the data from classification was converted from raster data to the vector data. From conversion result was obtained information of land cover class for every kind of land cover. Results of land cover class consist of building with area 3110, 79 ha, forest with area 1689,34 ha, farm with area $386,67 \mathrm{ha}$, and water body $830,35 \mathrm{ha}$.

Keywords : landsat image, classification, land cover

\section{Pendahuluan}

\subsection{Latar Belakang}

Aktivitas pembangunan pada kawasan perkotaan terus berkembang. Perkembangan pada kawasan perkotaan ditunjukkan dengan pemanfaatan ruang atau lahan perkotaan yang terus berkembang. Beberapa bentuk aktivitas pembangunan terus dilakukan pada setiap waktunya melalui berbagai pembangunan fasilitas perkotaan baik untuk fungsi sosial maupun ekonomi seperti pembangunan sarana permukiman, pusat-pusat bisnis atau perdagangan maupun fungsi-fungsi lainnya. Perkembangan perkotaan yang ditandai 
dengan semakin meningkatnya fasilitas fisik tidak menjamin area perkotaan dapat berjalan secaru tutupan lahan berkelanjutan oleh karenanya untuk mewujudkan area perkotaan yang berkelanjutan perlu dilakukan upaya pemantauan atau pengendalian terhadap perkembangan perkotaan itu sendiri. Salah satu upaya yang dapat dilakukan untuk mengetahui Perkembangan perkotaan adalah dengan melihat informasi tutupan lahan melalui peta tutupan lahan. Peta tutupan lahan dapat memberikan informasi pemanfaatan ruang kota secara spasial atau keruangan.

Informasi tutupan lahan sangat dibutuhkan oleh berbagai pihak. Penutupan lahan didefinisikan sebagai penyebutan kenampakan biofisik di permukaan bumi yang terdiri dari areal vegetasi, lahan terbuka, lahan terbangun, tubuh air dan lahan basah (Lillesand et al. 1990). Melalui peta tutupan lahan dapat diketahui informasi jenis-jenis tutupan lahan, luas dari setiap jenis tutupan lahan serta pola atau sebaran pemanfaatan ruang pada suatu wilayah. Informasi yang disajikan dalam peta tutupan lahan dapat dimanfaatkan untuk berbagai kegiatan seperti penelitian maupun berbagai kegiatan lainnya. Penelitian yang dapat dilakukan diantaranya melihat perubahan tutupan lahan yang menyajikan informasi perbandingan luas tutupan lahan pada dua peridoe waktu yang berbeda, dampak tutupan lahan terhadap kondisi lingkungan, kesesuaian pemanfaatan ruang terhadap kondisi lingkungan maupun rencana tata ruang maupun beberapa kegiatan penelitian lainnya. Hasil dari berbagai penelitian tesebut dapat dijadikan referensi bagi pihak pemerintah maupun pihak terkait lainnya untuk dapat memantau atau mengontrol perkembangan suatu wilayah.

Citra satelit merupakan salah satu media yang dapat digunakan untuk memperoleh informasi tutupan lahan. Pemanfaatan citra landsat telah banyak digunakan untuk beberapa kegiatan survey maupun penelitian (Wahyunto et al., 1995). Melalui citra satelit dapat dilakukan proses klasifikasi untuk mendapatkan informasi jenis-jenis tutupan lahan pada suatu wilayah berikut sebarannya secara spasial atau keruangan. Citra satelit merupakan data permukaan bumi yang diperoleh melalui perekaman oleh satelit. Data satelit kemudian ditangkap dan diproses oleh stasiun bumi yang kemudian dapat digunakan untuk pengolahan data maupun analisa yang terkait dengan permasalahan kebumian termasuk juga permasalahan perkotaan. Seiring perkembangan zaman dan teknologi identifikasi suatu wilayah bisa dilakukan dengan mudah dan cepat. Salah satunya ialah dengan pemanfaatan teknologi penginderaan jauh dan sistem informasi geografis.

\subsection{Tujuan}

Penelitian ini bertujuan untuk menganalisis pemanfaatan citra landsat untuk menentukan klasifikasi tutupan lahan pada area perkotaan Kota Palu menggunakan sistem informasi geografis. 


\section{Metode}

\subsection{Lokasi dan Waktu}

Penelitian dilakukan di wilayah perkotaan Kota Palu, Provinsi Sulawesi Tengah. Penelitian dilaksanakan selama 4 bulan dimulai sejak bulan Januari sampai dengan April 2017.

\subsection{Alat dan Bahan}

Alat-alat yang digunakan dalam penelitian ini adalah seperangkat komputer, alat tulis dan perangkat lunak (software) untuk penyusunan naskah, pengolahan dan analisis data. Perangkat lunak yang digunakan terdiri dari Arc GIS 10, Microsoft Office dan Excell 2007.

\subsection{Metode Penelitian}

Metode dalam penelitian ini meliputi pengumpulan data-data dan informasi yang diperlukan serta menganalisis data-data sesuai dengan kebutuhan dan tujuan studi.

\subsubsection{Teknik Pengumpulan Data Dan Jenis Data}

Jenis data yang diperlukan adalah data primer dan data sekunder. Data primer diperoleh dengan cara observasi ke lokasi atau obyek penelitian serta melakukan diskusi dan wawancara langsung dengan stakeholder. Data sekunder diperoleh dengan cara menelusuri berbagai sumber seperti hasil penelitian dan dokumen ilmiah dari instansi terkait.

\subsubsection{Analisis Data}

Analisis pemanfaatan citra landsat untuk klasifikasi tutupan lahan lanskap perkotaan kota palu meliputi analisis yang mencakup langkah-langkah sebagai berikut :

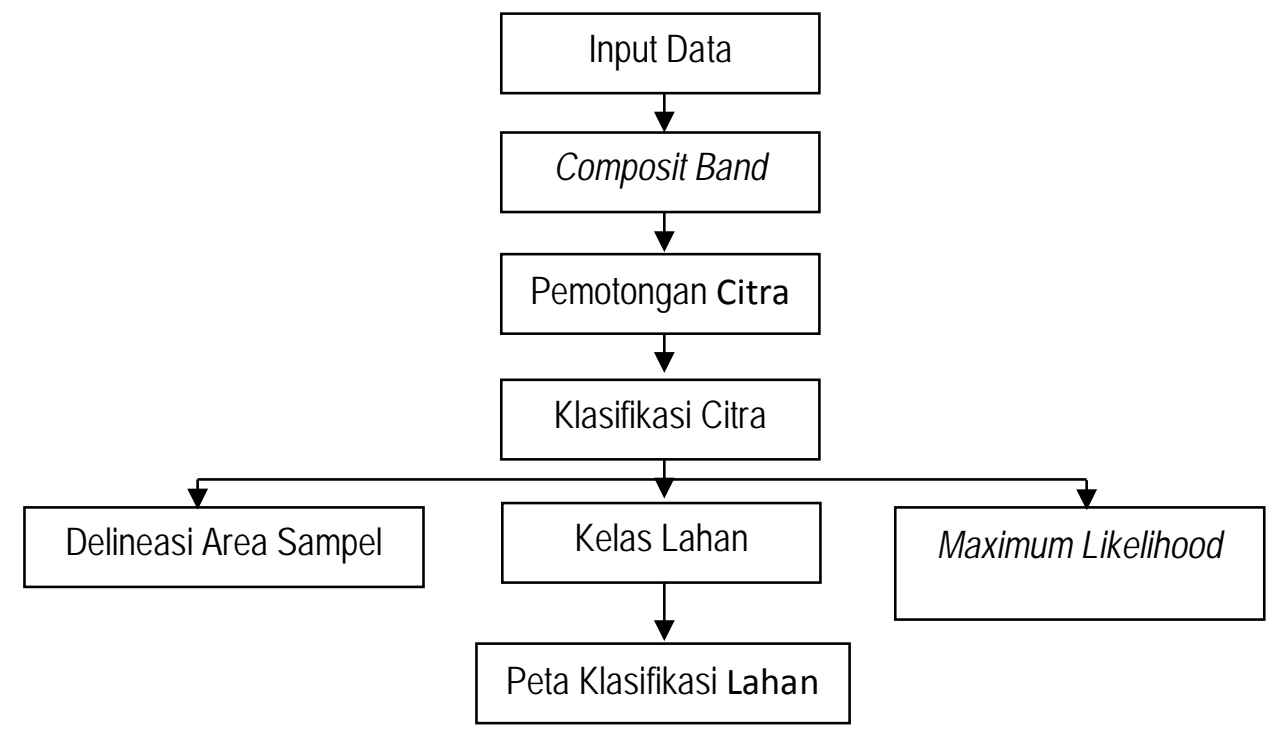

Gambar 1. Tahapan Klasifikasi Citra 


\section{Hasil Dan Pembahasan}

\subsection{Pengolahan Data Citra}

Pengolahan data citra diawali dengan menginput data citra landsat 8 (OLI) yang telah didownload kedalam aplikasi ArcGIS, selanjutnya data citra satelit yang terdiri dari 12 band digabung melalui proses composit band. Proses composit band dilakukan dengan fasilitas arctoolbox dengan cara menggunakan tool data management tools kemudian masuk ke raster selanjutnya ke menu raster processing dan composit bands.

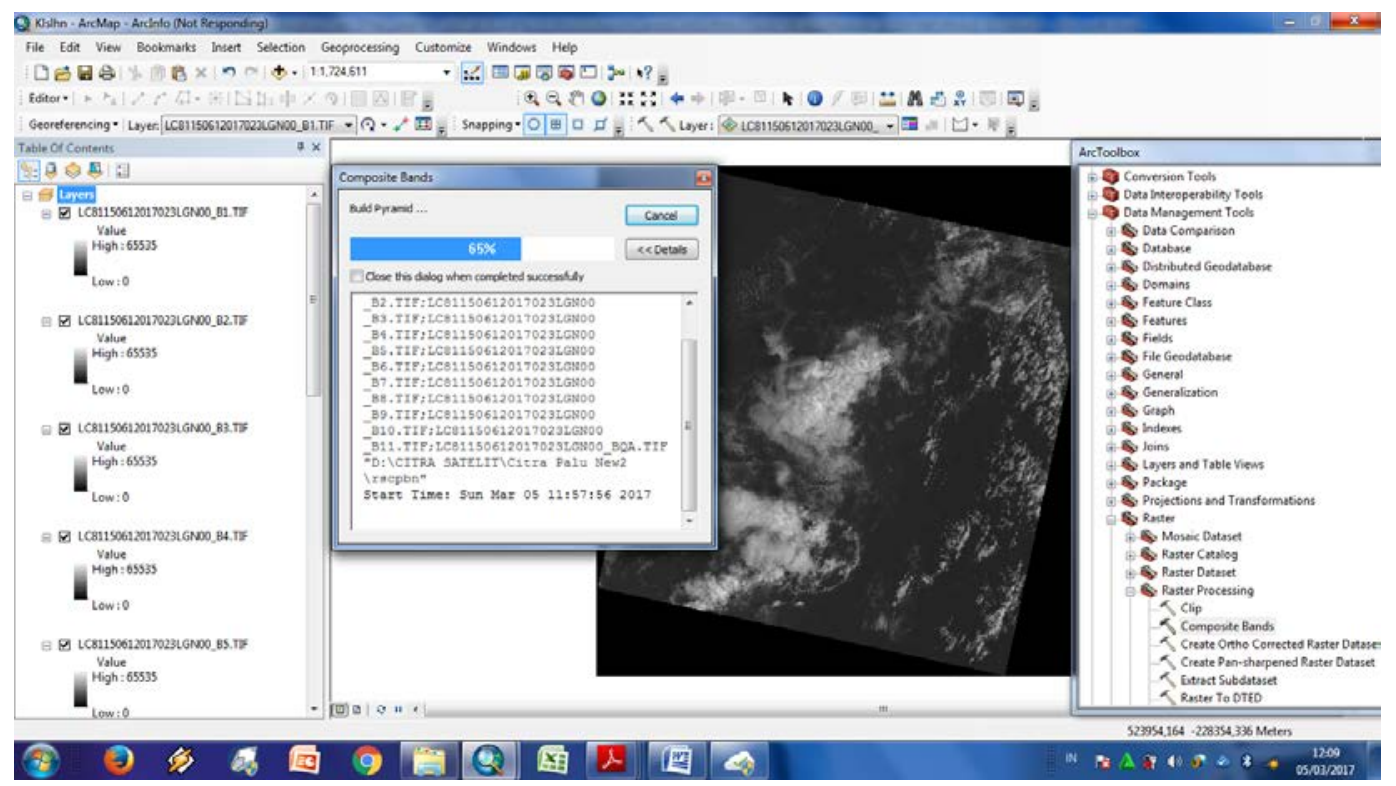

Gambar 1. Composit Bands Citra

Tahap selanjutnya adalah melakukan pemotongan citra landsat. Pemotongan citra landsat dilakukan dengan menggunakan tools yang sama pada saat melakukan composit band yaitu dengan menggunakan tool data management tools, raster dan raster processing selanjutnya masuk ke menu clip raster untuk melakukan pemotongan citra yang telah digabung. Sebelum melakukan proses clip atau pemotongan raster dilakukan pembuatan batas area pemotongan. Penentuan batas area pemotongan ditentukan berdasarkan objek yang akan diamati. 


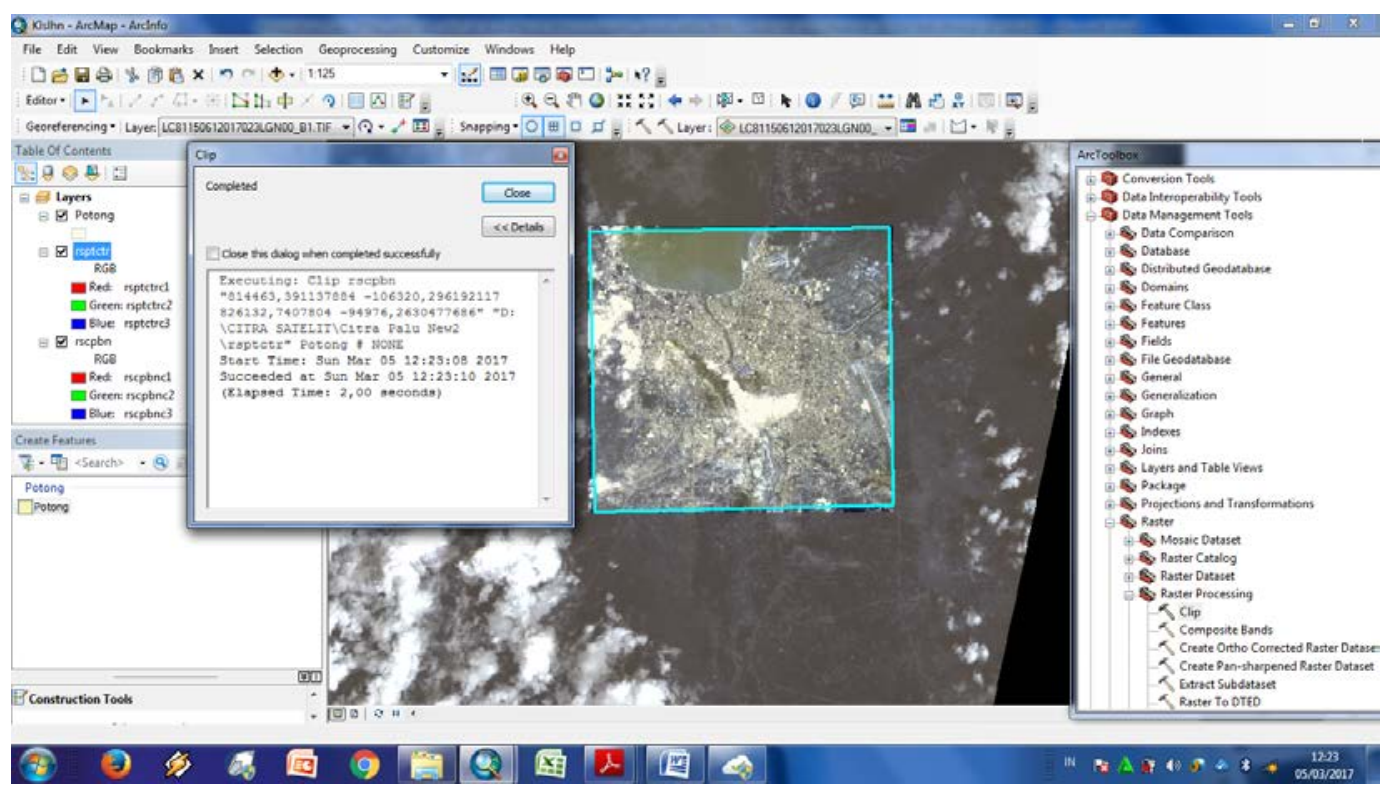

Gambar 2. Pemotongan (Cropping) Citra

Tahap berikutnya adalah melakukan koreksi geometrik. Koreksi geometrik dilakukan pada citra landsat yang telah dipotong. Koreksi geometrik dilakukan untuk menyesuaikan koordinat pada citra dengan koordinat lokasi atau objek yang akan diamati.

Tahap selanjutnya adalah klasifikasi citra. Klasifikasi citra dilakukan untuk menentukan kelas tutupan lahan berikut informasi jenis tutupan lahannya. Klasifikasi citra dilakukan dengan menggunakan menu image classification yaitu diawali dengan mendelineasi area sampel untuk setiap masing-masing tutupan lahan. Delineasi sampel tutupan lahan didasarkan pada kesamaan ciri pada setiap jenis tutupan lahan. Delienasi area sampel dilakukan dengan mengambil dua atau lebih sampel.

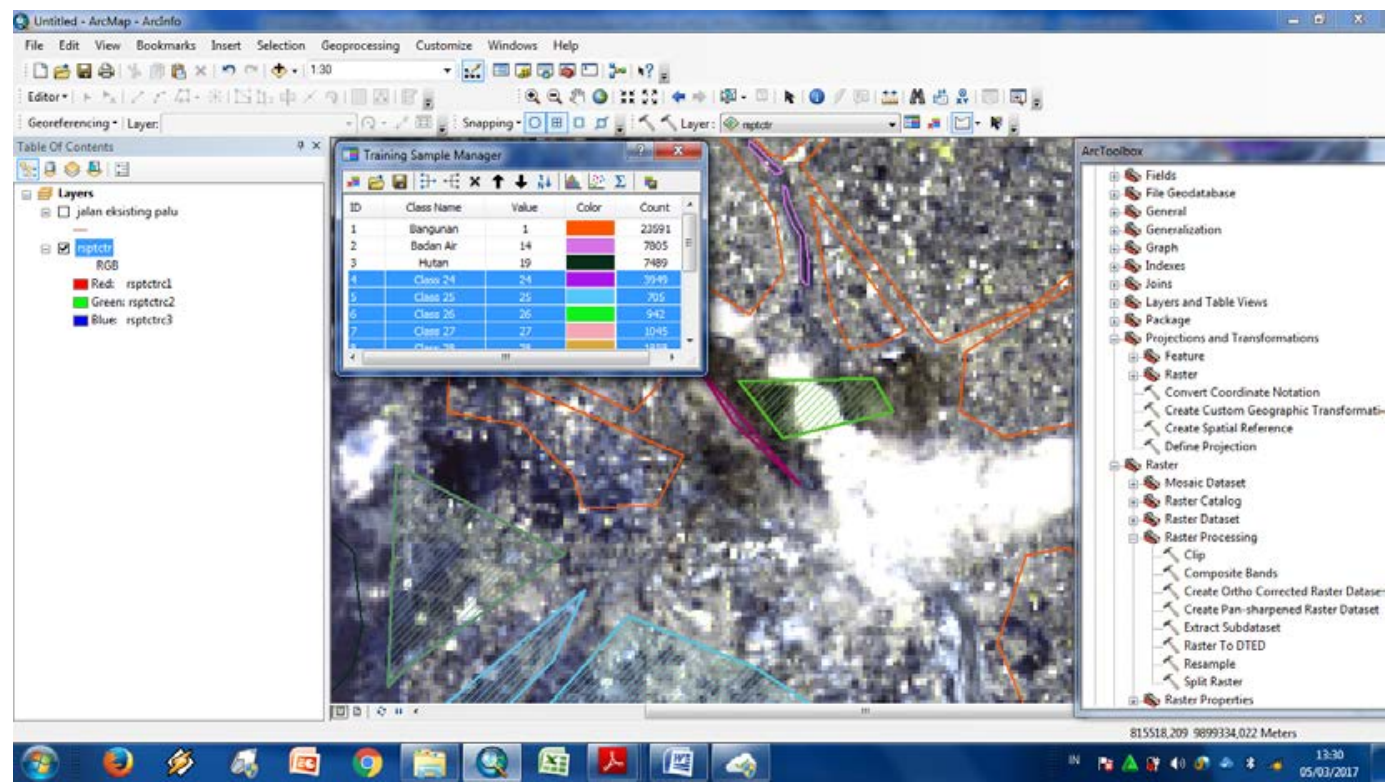

Gambar 3. Delineasi Area Sampel Citra 


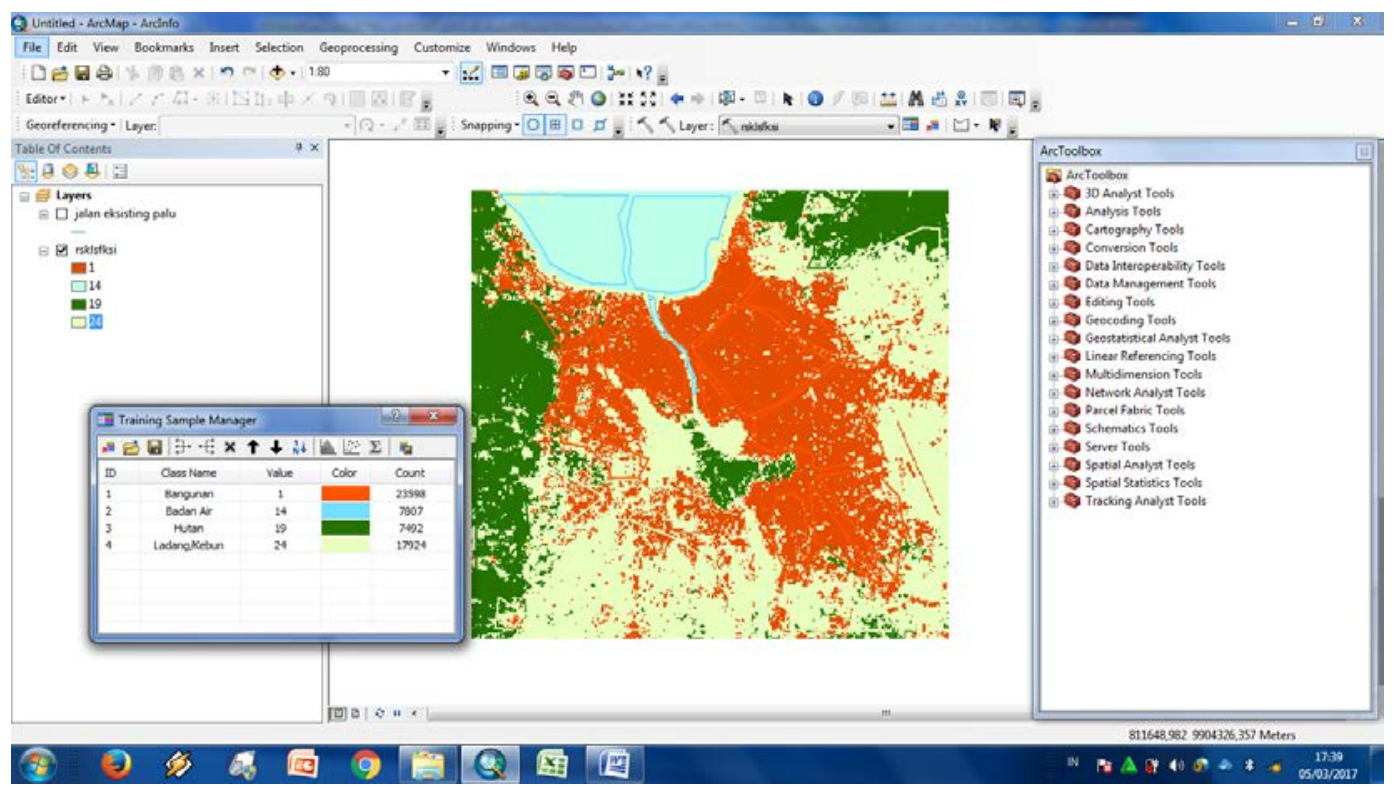

Gambar 4. Klasifikasi Citra Dalam Bentuk Raster

Dari beberapa sampel yang diambil untuk setiap jenis tutupan lahan dilakukan penggabungan sampel untuk menentukan satu jenis kelas tutupan lahan, hal yang sama juga dilakukan pada sampel tutupan lahan lainnya. Setelah dilakukan penggabungan sampel tutupan lahan selanjutnya adalah menentukan nama pada setiap jenis tutupan lahan yang diikuti oleh proses klasifikasi untuk menghasilkan data raster kelas lahan.

\subsection{Hasil Klasifikasi Citra}

Pada tahap akhir klasifikasi citra data raster hasil klasifikasi citra dikonversi menggunakan tool conversion tools menggunakan menu from raster, ratser to polygon. Hasil konversi data raster diperoleh data hasil klasifikasi dalam format vektor. Dari hasil konversi citra dalam format shapefile diperoleh informasi kelas tutupan lahan dan luas untuk setiap jenis tutupan lahan. Kelas lahan yang dihasilkan terdiri dari area terbangun dengan luas 3110,793 ha, hutan memiliki luas 1689, 341 ha, ladang/kebun memiliki luas 386,676 ha, badan air memiliki luas 830,357 ha.

Tabel 1. Klasifikasi dan Luasan Tutupan Lahan Area Perkotaan Kota Palu

\begin{tabular}{cc}
\hline Kelas Tutupan Lahan & Luas $(\mathrm{Ha})$ \\
\hline Terbangun & $3,110,793$ \\
Hutan & $1,689,341$ \\
Ladang/Kebun & 386,676 \\
Badan Air & 830,357 \\
\hline
\end{tabular}




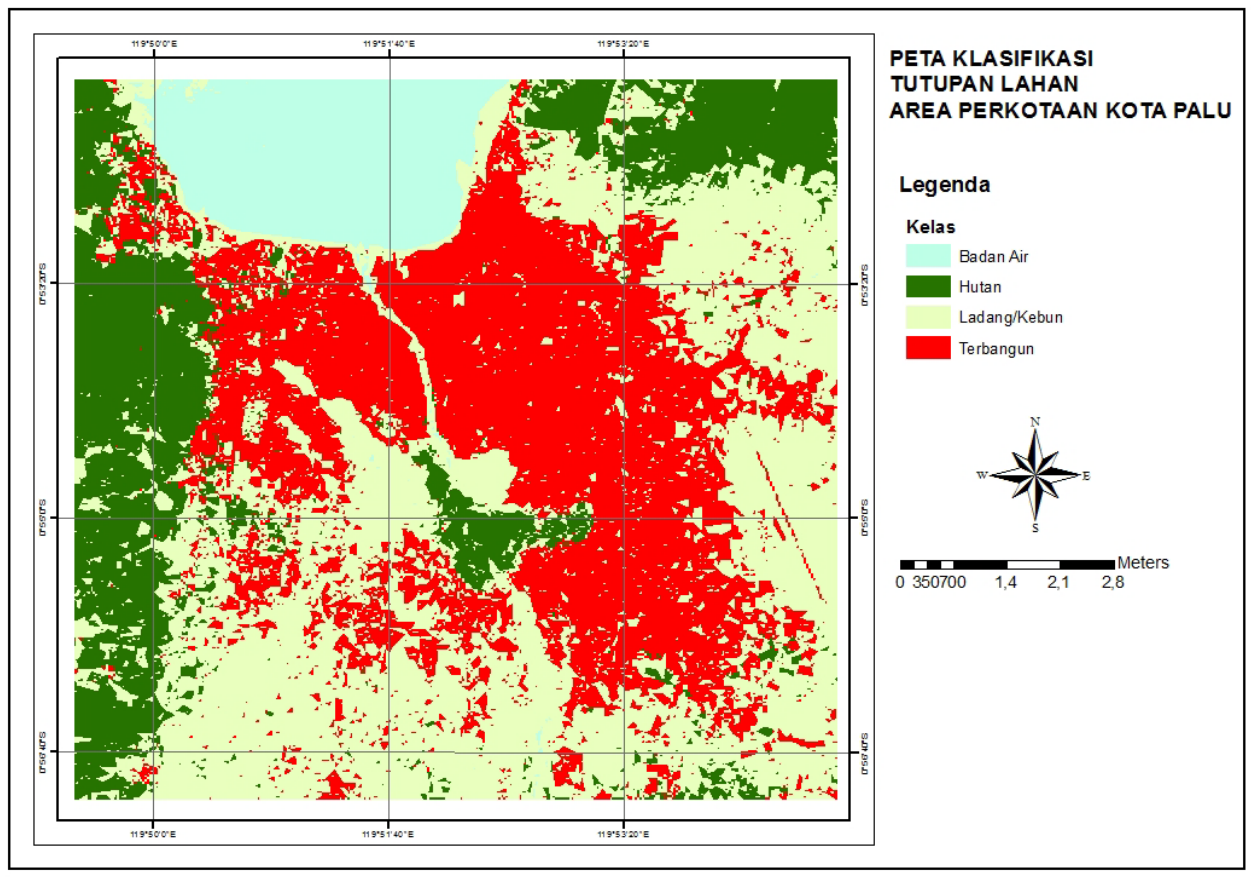

Gambar 5. Peta Klasifikasi Tutupan Lahan Area Perkotaan Kota Palu

\section{KESIMPULAN}

1. Proses klasifikasi citra diawali dengan penggabungan band dan pemotongan citra, koreksi geometrik dan klasifikasi menggunakan image classification dan selanjutnya mengkonversi data hasil klasifikasi dari format raster ke vektor.

2. Dari hasil konversi diperoleh informasi kelas tutupan lahan dan luas untuk setiap jenis tutupan lahan. Kelas lahan yang dihasilkan terdiri dari area terbangun dengan luas 3110,793 ha, hutan memiliki luas 1689, 341 ha, ladang/kebun memiliki luas 386,676 ha, badan air memiliki luas 830,357 ha.

\section{DAFTAR PUSTAKA}

Chapin F. Stuart And Edward J. Kaiser. 1979. Urban Land Use Planning. University Chicago : University Of Illionis Press.

Ritohardoyo, Su. 2009. Pemanfaatan Lahan Hutan Rakyat Dan Kehidupan Sosial Ekonomi Penduduk : Kasus Di Daerah Kabupaten Gunung Kidul. Disertasi, Sekolah Pascasarjana Ugm, Yogyakarta.

Kaiser, Et Al. 1995. Urban Land Use Planning.4th Edition. Chicago: UniveristyOf Illinois.

Eko, Mlati Trigus. Rahayu, Sri. 2012 Perubahan Penggunaan Lahan Dan Kesesuaiannya

Terhadap Rdtr Di Wilayah Peri-Urban Studi Kasus: Kecamatan Mlati. Jurnal 
Pembangunan Wilayah Dan Kota Biro Penerbit Planologi Undip Volume 8 (4) : 330340

Wahyuni, Sri. 2015 Identifikasi Karakteristik Dan Pemetaan Tutupan Lahan Menggunakan Citra Landsat 8 (Oli) Di Kabupaten Ogan Komering llir Provinsi Sumatera Selatan. Departemen Manajemen Hutan Fakultas Kehutanan Institut Pertanian Bogor Bogor.

Fariz, Hasbi. Atmawidjaja, Rudie R, Kresnawati DiahKirana. Identifikasi Penutup Lahan Menggunakan Citra Satelit Spot 4. Program Studi Teknik Geodesi, Fakultas Teknik, Universitas Pakuan, Jl. Pakuan, Bogor

Identifikasi Penggunaan Lahan Dengan Menggunakan Citra Landsat Thematic Mapper IpinSaripin 1 Buletin Teknik Pertanian Vol. 8. Nomor 2, 2003

Wahyunto, Sunyoto, Supanni, Dan Marsoedi Ds. 1993. Penggunaan Citra Landsat Berwarna Untuk Menunjang Identifikasi Dan Inventarisasi Lahan Kritis Di Daerah Propinsi Sumatera Utara. HIm. 23-31. Dalam Prosiding Pertemuan Teknis Penelitian Tanah Dan Agrok1imat, Bogor, 18-21 Februari, 1993. PusatPenelitian Tanah Dan Agroklimat, Bogor. 